\title{
Bi-Function Multi-Beam Graphene Lens Antenna for Terahertz Applications
}

\author{
Saber H. Zainud-Deen'1, Walaa M. Hassan'2, Hend A. Malhat ${ }^{1}$ \\ ${ }^{1}$ Faculty of Electronic Engineering, Menoufia University, Menouf, Egypt \\ ${ }^{2}$ Electronics Research Institute, Giza, Egypt \\ Email: walaa81hassan@yahoo.com,er_honida1@yahoo.com
}

Received 29 December 2015; accepted 25 January 2016; published 28 January 2016

Copyright (C) 2016 by authors and Scientific Research Publishing Inc.

This work is licensed under the Creative Commons Attribution International License (CC BY). http://creativecommons.org/licenses/by/4.0/

(c) (i) Open Access

\begin{abstract}
Bi-function Compact graphene lens antenna in terahertz (THz) band has been investigated. The array function is switched between two status, reflectarray and/or transmitarray. The tunability of graphene conductivity introduces the bi-function characteristics of a single array structure in the THz band. The design depends on changing the graphene DC biasing voltage to transform the transmitting antenna to reflecting antenna. The compact structure of the antenna array saves the cost and the allocation area for the terahertz communication applications. A $13 \times 13$ reflectarray/ transmitarray antenna covering an area of $364 \times 364 \mu \mathrm{m}^{2}$ is proposed. A dual-beams reflectarray/transmitarray antenna is achieved by rearranging the cell elements of the array successively. Finally, a single structure is used to work as reflectarray and transmitarray antenna at the same time by rearranging the applied voltages between the different pieces of the graphene sheet using chess board arrangement. The phases of the successive unit-cells are kept the same of their locations in the original full array. The radiation characteristics of the array are investigated using the CST Microwave Studio for the bi-function operation.
\end{abstract}

\section{Keywords}

Reflectarray, Transmitarray, Graphene, Single/Dual-Beam Antenna, THz Applications

\section{Introduction}

Enormous applications have been introduced due to the development of the terahertz science and technology. The terahertz applications are spectroscopy, communication, defense, and biomedical imaging [1]. High gain antennas are introduced in many applications such as parabolic reflector, dielectric lens and phased array which are used. However, the parabolic antenna is bulky and heavy and the phased array has complex feeding net- 
works [2]-[4]. The reflectarray/transmitarray antennas are good alternatives to parabolic reflectors/lenses because of their low profile, simple manufacturing process, and low cost especially for beam shaping applications [5] [6]. The reflectarrays combine certain advantages of reflector antennas and phased arrays. The reflectarray/ transmitarray is constructed using unit cells arranged in a planar structure and are illuminated by incident wave. The antenna unit cells are tuned in order that the phase of the reflected/transmitted wave to produce a focused or shaped beam when illuminated by a primary feed [7]-[9]. Different methods to control the phase of the re-radiated wave have been introduced such as using elements with variable sizes, slots with variable lengths on the ground plane, and microstrip reflectarray with elements having variable rotation angles [10]. There are several designs for reflectarray and transmitarray using dipoles, microstrip patches, and dielectric resonator antennas which have been investigated [11]-[15].

Graphene has attracted the attention of the research community due to its novel characteristics [16]. Graphene is a planar atomic layer of carbon atoms bonded in a hexagonal structure [17]. Graphene is a promising material for the realization of miniaturized resonant $\mathrm{THz}$ antennas. Recently, graphene has been investigated due to its attractive physical properties, such as strong conductivity, good transparency and notable medium nonlinearity [18]. The graphene material supports surface plasmon polarities in the $\mathrm{THz}$ range that are widely tunable by a change of graphene's conductivity via chemical doping, or magnetic field or electrostatic gating [19]. Different graphene based antennas have been investigated recently. In [20], the radiation characteristics of dipole antenna array were controlled by switching between the low- and high-resistivity states of graphene ground plane. The equivalent circuit of graphenemicrostrip antenna for $60 \mathrm{GHz}$ communications and the impact of graphene chemical potential on their radiation characteristics have been investigated. A design of tunable graphene reflectarray with generalized law of reflection has been introduced in [21] [22]. In [23], a design of graphene based transmitarray for terahertz applications has been proposed using graphene dual rings sheets. Recently, plasma material has been used for the design of a reflectarray/transmitarray in a single structure for satellite applications [24]. There are novelty researchers for graphene in reflectarray applications as discussed in [25] [26].

In this paper, a single structure of perforated dielectric sheet with inserted graphene sheet has been proposed for reflectarray and transmitarray antenna operation using a single DC-bias. The radiation characteristics of this single structure in the reflectarray mode and the transmitarray mode have been investigated. Dual-beam reflectarray and transmitarray antenna can be obtained using successive unit-cell elements arrangement. The radiation characteristics of reflectarray and transmitarray in the same time using the same structure have been investigated. The reflectarray and transmitarray unit cell elements are arranged in a chess board arrangement. The antenna structures are simulated and investigated using the CST Microwave Studio [27].

\section{Graphene Material Properties}

Graphene is a 2-D carbon sheet in which the atoms are arranged in a honeycomb lattice structure. Graphene can be modeled as infinitely thin surface of complex conductivity $\sigma$. The complex surface conductivity of a monolayer graphene sheet is represented by [28]:

$$
\sigma(\omega)=\sigma_{\text {intra }}(\omega)+\sigma_{\text {inter }}(\omega)
$$

where

$$
\begin{gathered}
\sigma_{\text {intra }}(\omega) \approx-j \frac{q_{e}^{2} k_{B} T}{\pi \hbar(\omega-j 2 \Gamma)} \times\left(\frac{\mu_{c}}{k_{B} T}+2 \ln \left(\mathrm{e}^{-\mu_{c} / k_{B} T}+1\right)\right) \\
\sigma_{\text {inter }}(\omega) \approx-j \frac{q_{e}^{2}}{4 \pi \hbar} \ln \left(\frac{2\left|\mu_{c}\right|-\left(\omega-j \tau^{-1}\right) \hbar}{2\left|\mu_{c}\right|+\left(\omega-j \tau^{-1}\right) \hbar}\right)
\end{gathered}
$$

$\sigma_{\text {intera }}(\omega)$ is intraband term, $\sigma_{\text {inter }}(\omega)$ is the interband term, $j$ is the imaginary unit, $q_{e}$ is the electron charge, $\hbar=h / 2 \pi$ is the reduced Planck's constant, $k_{B}$ is the Boltzman's constant, $\tau$ is the transport relaxation time, $T$ is the temperature, $\omega$ is the operating angular frequency, the scattering rate $\Gamma=1 / 2 \tau$ represents loss mechanism, and $\mu \mathrm{c}$ is the chemical potential. The later parameter $\mu \mathrm{c}$ is affected by the externally applied voltage. In this paper, the following parameters are considered: $T=300 \mathrm{~K}$ and $\tau=1 \mathrm{ps}$. The intraband term of the conductivity given by Equation (1) is dominated in the frequency range below $8 \mathrm{THz}$ and interband contribution can 
be neglected [28]. Figure 1 shows the resulting complex conductivity in the band from 1 to $7 \mathrm{THz}$ at different values of chemical potential $\mu_{c}$. The graphene layer behaves as a constant resistance in series with an inductive reactance that increases with increasing frequency. The graphene material is represented by a surface impedance of $8.52+j 321.57 \Omega$. The relationship between the applied electric field and the chemical potential, $\mu_{c}$, can be calculated by [29]:

$$
E=\frac{q_{e}}{\pi \hbar^{2} v_{F}^{2} \varepsilon_{o}} \int_{0}^{\infty} \epsilon\left(f_{d}(\epsilon)-f_{d}\left(\epsilon+2 \mu_{c}\right)\right) \mathrm{d} \epsilon
$$

where $f_{d}(\epsilon)$ is the Fermi-Dirac distribution and is given by

$$
f_{d}(\epsilon)=\left(\mathrm{e}^{\left(\epsilon-\mu_{c}\right) / k_{B} T}+1\right)^{-1}
$$

where $d$ is the thickness of the graphene sheet, and $v_{F}$ is the electron's energy independent velocity $\left(v_{F} \approx 10^{6}\right.$ $\mathrm{m} / \mathrm{s}$ ). The relationship between the complex conductivity and biasing electric field of the graphene sheet is shown in Figure 2. The conductivity of the graphene is increased as the applied electric field is increased. A curve fitting for the real and imaginary conductivity as a function of applied electric field is concluded as straight line from Equation (2) and Equation (4) and given by

$$
\begin{aligned}
& \sigma_{\text {Real }}=p_{1} E+p_{2} \\
& \sigma_{\text {Img }}=p_{3} E+p_{4}
\end{aligned}
$$

where $p_{1}=1.0526 \times 10^{-5}, p_{2}=9.6588 \times 10^{-7}, p_{3}=-3.97 \times 10^{-4}$, and $p_{4}=-3.6413 \times 10^{-5}$.

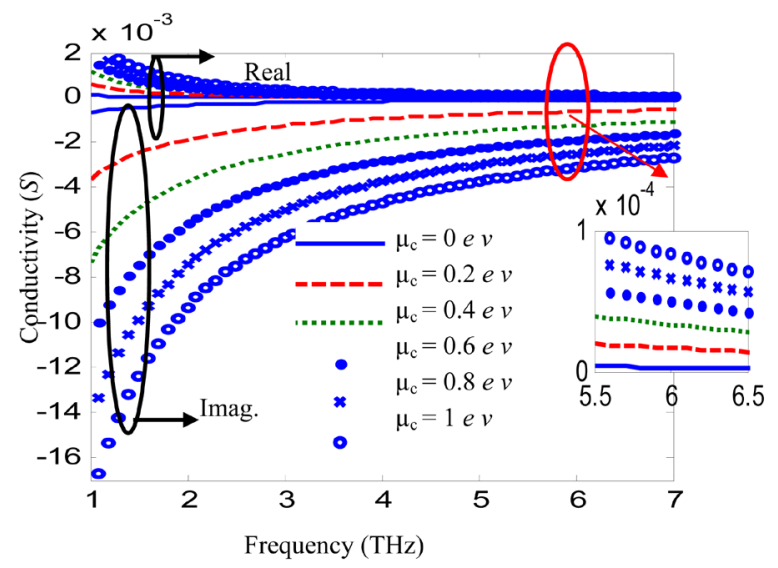

Figure 1. The graphene conductivity versus the frequency at different values of chemical potential $\mu_{c}, T=300^{\circ} \mathrm{K}$, and $\tau=1$ psec.

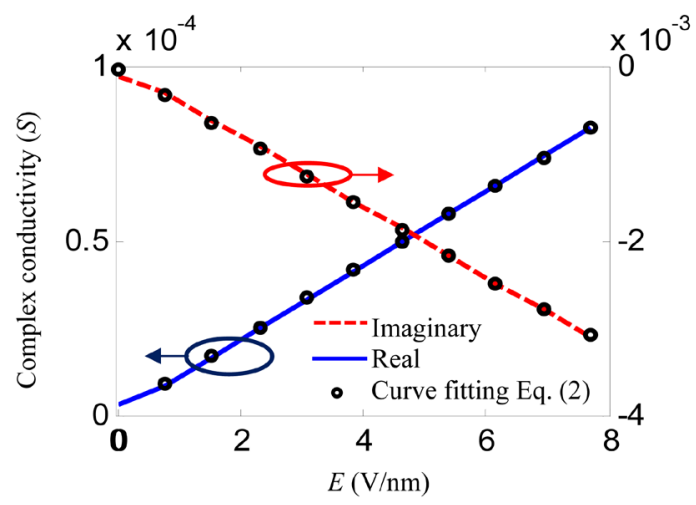

Figure 2. Real and imaginary conductivity versus the bias field. 


\section{Unit-Cell Design}

The detailed dimensions of the proposed unit-cell element are shown in Figure 3. The unit-cell element consists of a square perforated dielectric box, with arm length $L_{1}=28 \mu \mathrm{m}$, thickness $h=12.5 \mu \mathrm{m}$, and dielectric constant $\varepsilon_{r}=12$ (HiK500F). The unit-cell element has four identical circular holes with radius r. A single graphene sheet is inserted between the two square dielectric boxes with sheet length $L_{2}=L_{1}-0.002 \mu \mathrm{m}$. The required phase and magnitude compensations of each unit-cell element are achieved by varying the holes radii using the waveguide simulator. A waveguide simulator has a perfect electric and perfect magnetic conductor boundary conditions to assume an infinite array [10].

Two cases for the graphene sheet are considered for the unit cell element. In the first case, the graphene sheet is considered as a conductor with $\mu_{c}=1$, while in the second case, the graphene sheet is considered as a dielectric with $\mu_{c}=0$, by altering the DC applied voltage. The variations of the reflection coefficient phase and magnitude versus hole radius at $6 \mathrm{THz}$ for $\mu_{c}=1$, are shown in Figure 4(a). The reflection coefficient phase is varies from 0 to 360 degrees and reflected coefficient magnitude variations from 0 to $-0.5 \mathrm{~dB}$ for holes radii varies from 2.5 to $6.9 \mu \mathrm{m}$. The variations of the transmitted coefficient phase and magnitude versus holes radii at 6 $\mathrm{THz}$ for $\mu_{c}=0$ are shown in Figure 4(b). A transmitted coefficient phase is changed from 0 to 285 degrees with magnitude variations from 0 to $-6.5 \mathrm{~dB}$. An average phase is depicted for $\mu_{c}=1$ and $\mu_{c}=0$. Abrupt change in reflected/transmitted magnitude is due to reflected wave from the perforated dielectric sheet, which acts as a circular waveguide with different radii results in different resonance frequencies. Phase variation for the design of transmitarray and reflectarray in a single structure is shown in Figure 5.

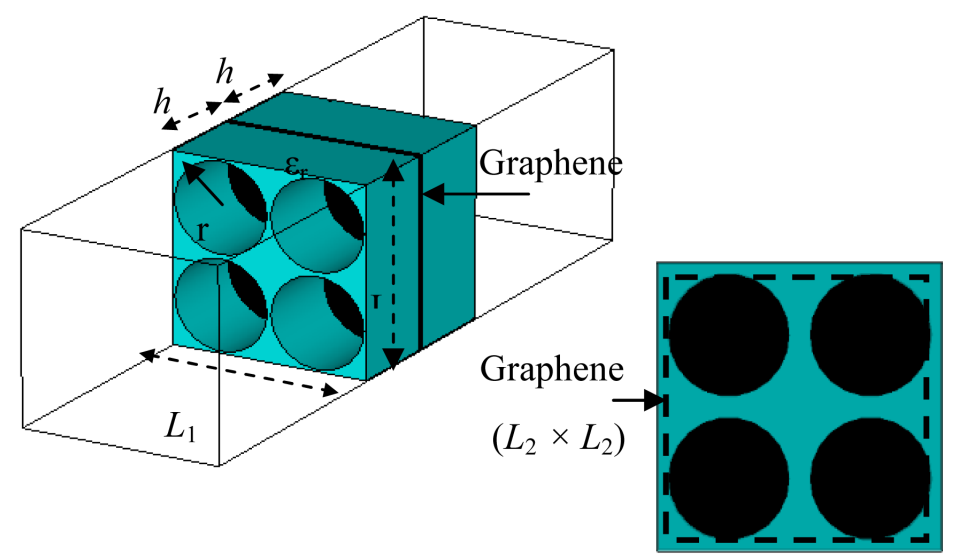

3D view Front view

Figure 3. The configuration of the proposed unit cell.

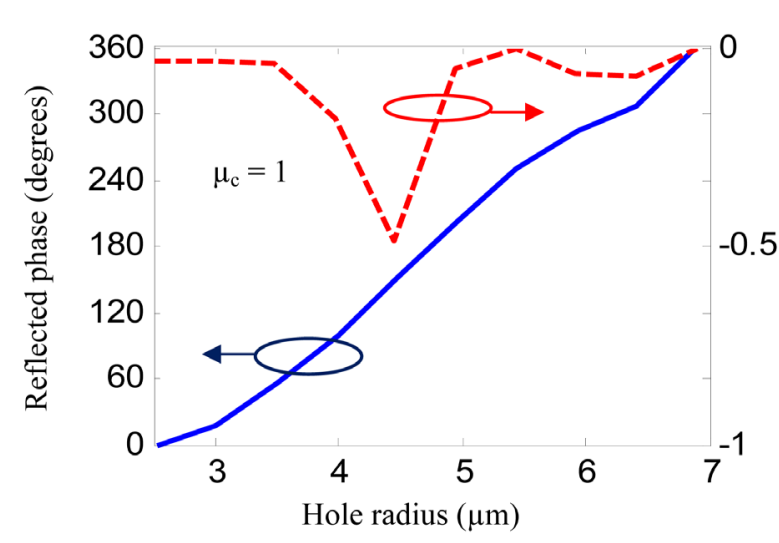

(a)

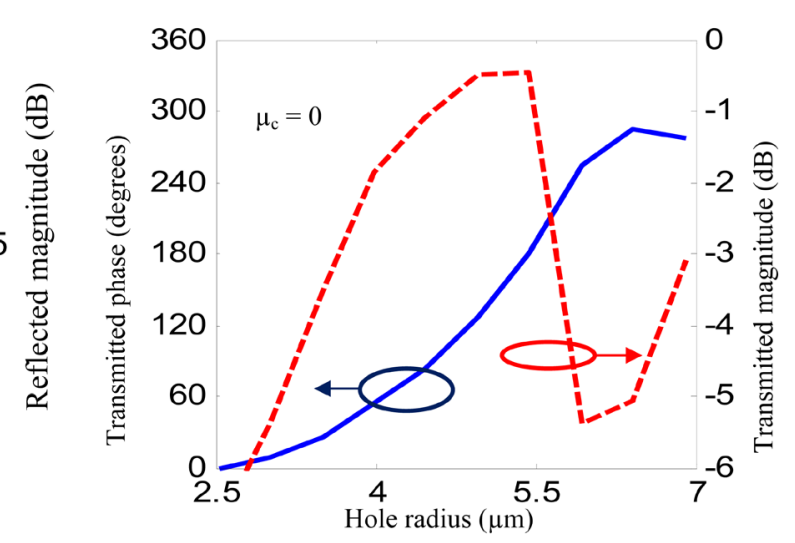

(b)

Figure 4. (a) The reflected phase and magnitude variations versus the hole radius at $6 \mathrm{THz}$ at $\mu_{c}=1$, (b) the transmitted phase and magnitude variations versus the hole radius at $6 \mathrm{THz}$ at $\mu_{c}=0$. 


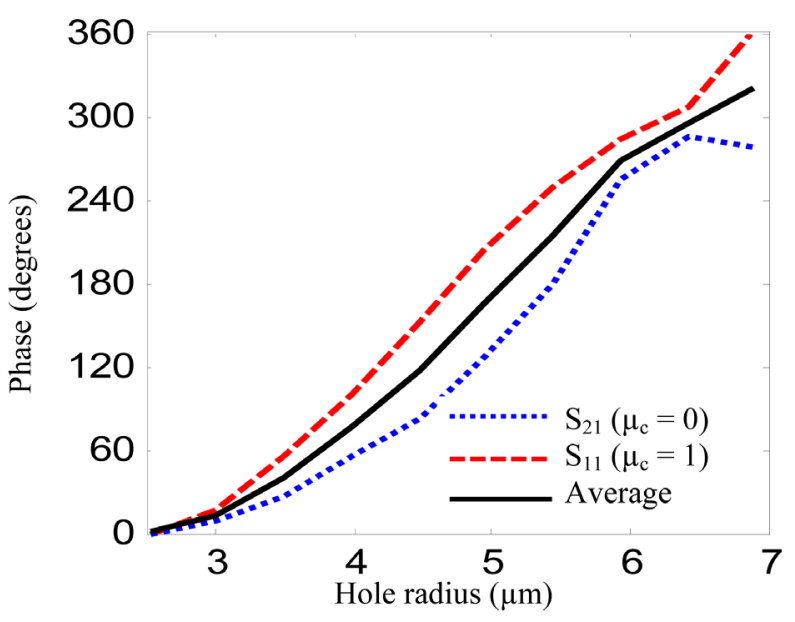

Figure 5. The phase and magnitude variations versus the hole radius of the unit cell at $6 \mathrm{THz}$.

\section{Design of the Reflectarray/Transmitarray in a Single Structure Using a Single DC-Bias}

Figure 6(a) shows the detailed construction of a $13 \times 13$ reflectarray/transmitarray placed in $\mathrm{x}-\mathrm{y}$ plane with total area of $364 \times 364 \mu^{2}$. The number of array elements is limited by the core (the cash memory) of the CPUmemory of the available computer. Separate pieces from the graphene sheet are considered for the unit cell elements arrangement in two modes of operation using a single DC-biasing. For $\mu_{c}=1$ the reflectarray mode dominates while for $\mu_{c}=0$ the transmitarray mode dominates without altering the array design. A circular horn antenna located at a distance F normal to the array aperture is used to feed the array structure. The horn has a circular aperture with radius $44 \mu \mathrm{m}$, waveguide outer radius $22 \mu \mathrm{m}$, and length $=83.1 \mu \mathrm{m}$. The required phase compensation distribution $\varphi_{i j}$ at each unit cell element in the array to collimate a beam in the $\left(\theta_{o}, \varnothing_{o}\right)$ direction is obtained by [6]:

$$
\begin{gathered}
\varphi_{i j}\left(x_{i j}, y_{i j}\right)=k_{o}\left[d_{i j}-x_{i j} \sin \left(\theta_{o}\right) \cos \left(\varnothing_{o}\right)-y_{i j} \sin \left(\theta_{o}\right) \sin \left(\varnothing_{o}\right)\right] \\
d_{i j}=\sqrt{\left(x_{i j}-x_{f}\right)^{2}+\left(y_{i j}-y_{f}\right)^{2}+z_{f}^{2}}
\end{gathered}
$$

$k_{o}$ is the propagation constant and $d_{i j}$ is the distance from the feed point $\left(x_{f}, y_{f}, z_{f}\right)$ to the $i j^{\text {th }}$ element in the array located at $\left(x_{i j}, y_{i j}\right)$. Figure 6 (b) shows the graphenetransmitarray phase distribution. The phase shift and the corresponding hole radius for reflectarray/transmitarray are shown in Table 1 . The E-plane and H-plane radiation patterns for reflectarray mode $\left(\mu_{c}=1\right)$ and the transmitarray mode $\left(\mu_{c}=0\right)$ and horn antenna at frequency 6 $\mathrm{THz}$ are shown in Figure 7. The reflectarray/transmitarray introduces maximum gain of $24.4 \mathrm{~dB} / 22 \mathrm{~dB}$ with the side lobe level (SLL) of $-16.5 \mathrm{~dB} /-12 \mathrm{~dB}$ in the E-plane and $-19.5 \mathrm{~dB} /-15 \mathrm{~dB}$ in the H-plane. The reflectarray/transmitarray has half-power beam width (HPBW) of $7.1^{\circ} / 8.6^{\circ}$ in the E-plane and $7.1^{\circ} / 9.1^{\circ}$ in the $\mathrm{H}$-plane. The gain variations versus frequency for the reflectarray/transmitarray mode of operation are shown in Figure 8(a). The 1-dB gain bandwidth is $1.07 \mathrm{THz} / 1 \mathrm{THz}$ with maximum gain occurs at $6 \mathrm{THz}$. Figure 8(b) and Figure 8(c) show the 3D radiation patterns for reflectarray/transmitarray.

\section{Design of the Dual Beam Reflectarray/Transmitarray in a Single Structure}

A dual-beam reflectarray mode $\left(\mu_{c}=1\right)$ is designed to achieved using the same array structure with single DC-bias. In this case, two separate arrays are designed one to give maximum beam at $\zeta=-20^{\circ}$ and the other is designed to give maximum beam at $\zeta=0^{\circ}$. The single structure is achieved by using the chess board arrangement. The chess board arrangement is constructed by rearranging its elements from the previous two arrays. The gain for $\zeta=0^{\circ}$ is $19.9 \mathrm{~dB}$ and for $\zeta=-20^{\circ}$ is $17.7 \mathrm{~dB}$. The 3D power pattern of the dual beam reflectarray in the same structure is shown in Figure 9(a). Power pattern of the dual beam reflectarray in the same structure is shown in Figure 9 (b). The HPBW is $7^{\circ}$ and $5.59^{\circ}$ for $\zeta=0^{\circ}$ and $\zeta=-20^{\circ}$ respectively. Similarly, A dual-beam 


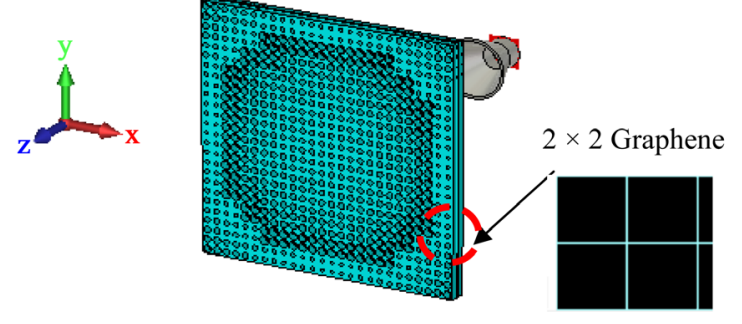

(a)

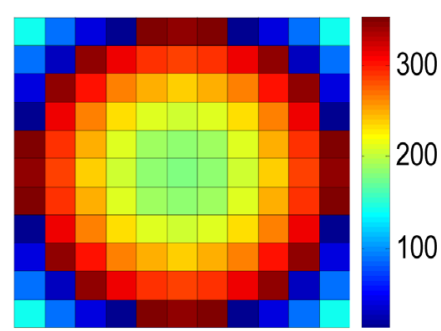

(b)

Figure 6. (a) The 3-D detailed construction of the configuration $13 \times 13$ reflectarray/Transmitarray, (b) graphene phase distribution.

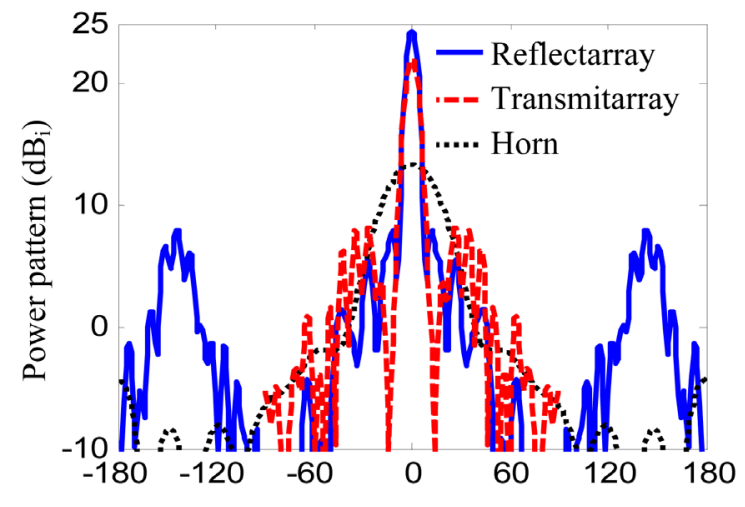

Elevation angle, $\theta / \zeta$ (degrees)

(a)

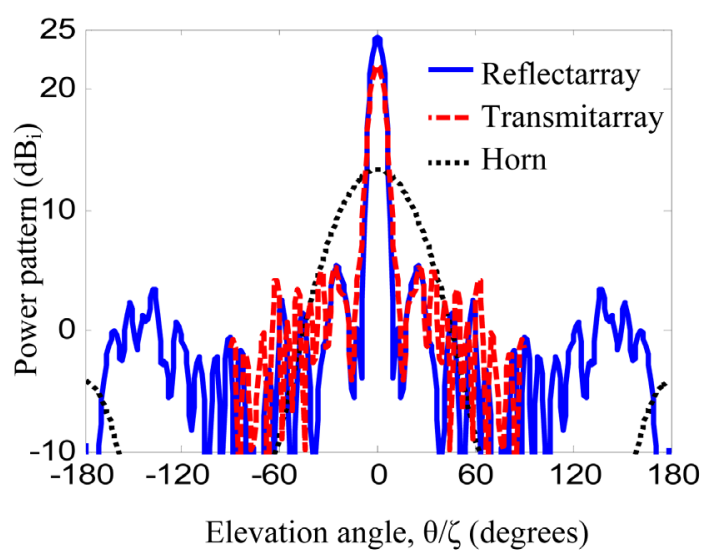

(b)

Figure 7. The E-plane and H-plane radiation patterns variations versus the elevation angle for $13 \times 13$ reflectarray/transmitarray with F/D = 1 and frequency 6 THz. (a) E-plane (x-z), (b) H-plane (y-z).

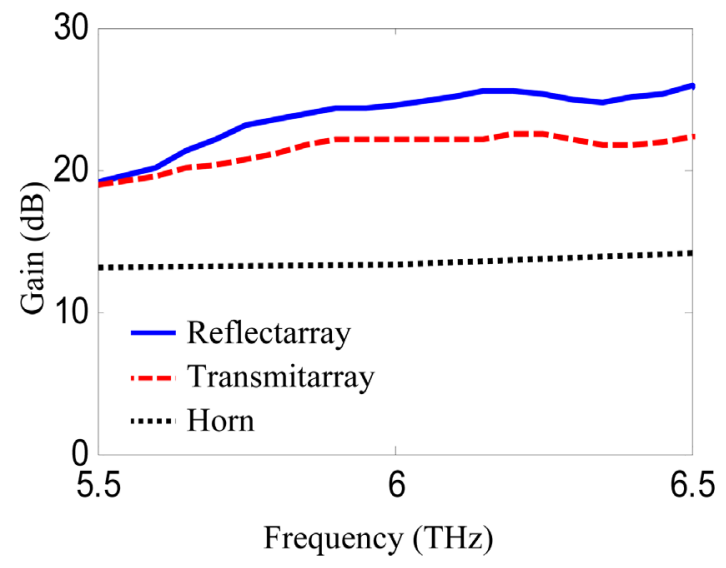

(a)

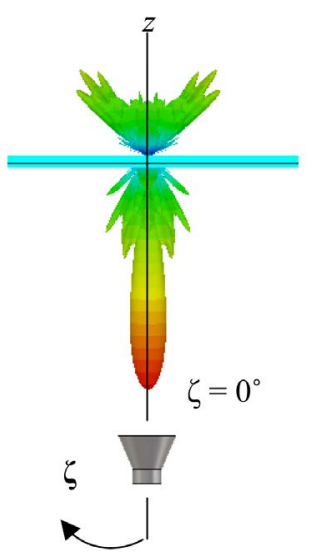

(b)

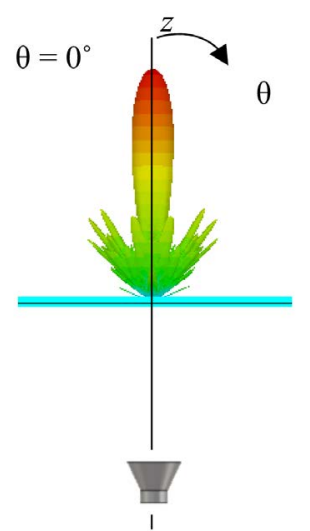

(c)

Figure 8. (a) The variations of the gain versus frequency for $13 \times 13$ reflectarray/transmitarray with $\mathrm{F} / \mathrm{D}=1$ at frequency $6 \mathrm{THz}$, (b) the 3-D power pattern for $13 \times 13$ reflectarray $\mu_{c}=1$, (c) the 3-D power pattern for $13 \times 13$ transmitarray $\mu_{c}=0$.

transmitarray mode $\left(\mu_{c}=0\right)$ is designed for two beams at $\theta=0^{\circ}$ and $\theta=20^{\circ}$ directions by using the chess board arrangement. The 3D power patterns of the transmitarray with two beams at $\theta=0^{\circ}$ and $\theta=20^{\circ}$ are shown in Figure 10(a). Power pattern of the dual beam reflectarray in the same structure is shown in Figure 10(b). A maximum gain of $16.9 \mathrm{~dB}$ is achieved for $\theta=0^{\circ}$ and $16.6 \mathrm{~dB}$ for $\theta=20^{\circ}$. The HPBW is $9^{\circ}$ and $8^{\circ}$ for $\theta=0^{\circ}$ and $\theta=-20^{\circ}$, respectively. 


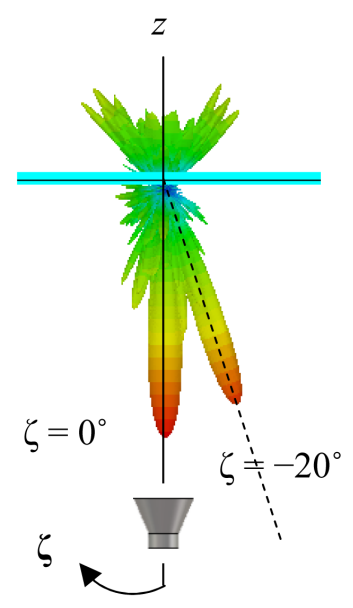

(a)

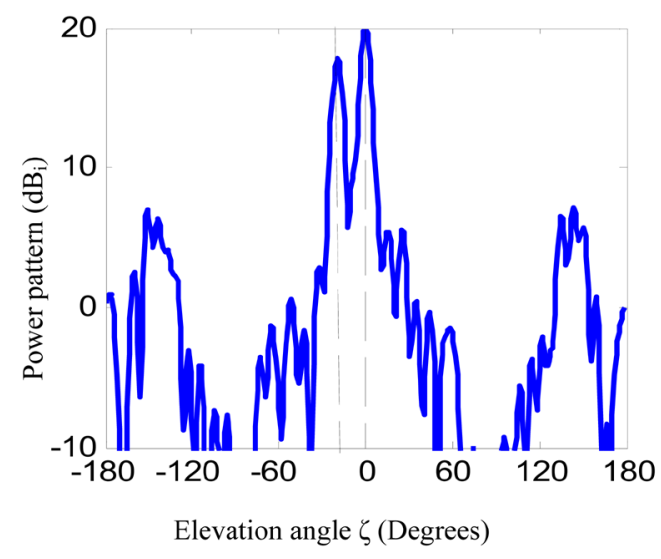

(b)

Figure 9. (a) The 3D power pattern of the dual beam reflectarray in the same structure, (b) power pattern of the dual beam reflectarray in the same structure.

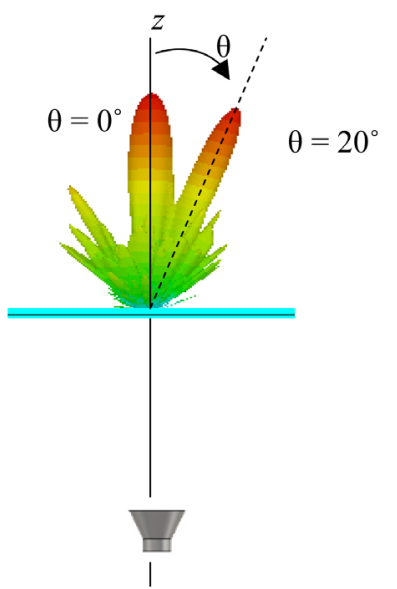

(a)

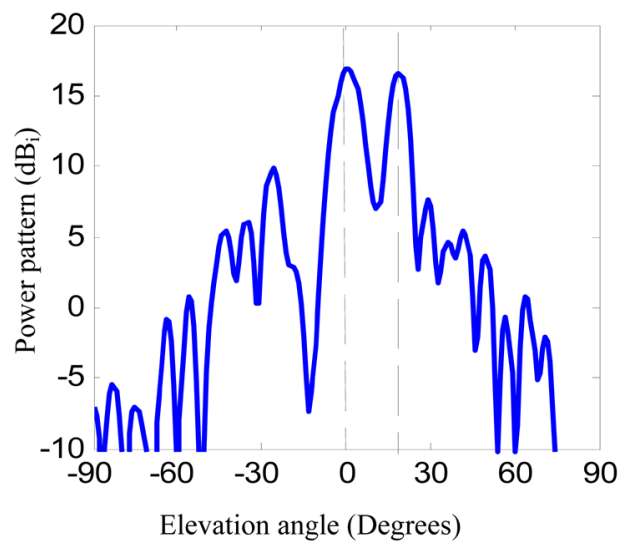

(b)

Figure 10. (a) The 3D power pattern of the dual beam transmitarray in the same structure; (b) power pattern of the dual beam transmitarray in the same structure.

Table 1. The phase shift and the corresponding hole radius for reflectarray/transmitarray.

\begin{tabular}{|c|c|c|c|c|c|c|}
\hline $100.8^{\circ}$ & $108.5^{\circ}$ & $131.6^{\circ}$ & $169.7^{\circ}$ & $222.1^{\circ}$ & $287.9^{\circ}$ & $6.472^{\circ}$ \\
\hline $4.27 \mu \mathrm{m}$ & $4.36 \mu \mathrm{m}$ & $4.62 \mu \mathrm{m}$ & $4.99 \mu \mathrm{m}$ & $5.51 \mu \mathrm{m}$ & $6.24 \mu \mathrm{m}$ & $2.78 \mu \mathrm{m}$ \\
\hline $108.5^{\circ}$ & $116.3^{\circ}$ & $139.3^{\circ}$ & $177.2^{\circ}$ & $229.5^{\circ}$ & $295.2^{\circ}$ & $13.51^{\circ}$ \\
\hline $4.36 \mu \mathrm{m}$ & $4.46 \mu \mathrm{m}$ & $4.70 \mu \mathrm{m}$ & $5.07 \mu \mathrm{m}$ & $5.56 \mu \mathrm{m}$ & $6.39 \mu \mathrm{m}$ & $3.01 \mu \mathrm{m}$ \\
\hline $131.6^{\circ}$ & $139.3^{\circ}$ & $162.1^{\circ}$ & $199.7^{\circ}$ & $251.5^{\circ}$ & $316.8^{\circ}$ & $34.49^{\circ}$ \\
\hline $4.62 \mu \mathrm{m}$ & $4.70 \mu \mathrm{m}$ & $4.92 \mu \mathrm{m}$ & $5.29 \mu \mathrm{m}$ & $5.74 \mu \mathrm{m}$ & $6.81 \mu \mathrm{m}$ & $3.40 \mu \mathrm{m}$ \\
\hline $169.7^{\circ}$ & $177.2^{\circ}$ & $199.7^{\circ}$ & $236.8^{\circ}$ & $287.9^{\circ}$ & $352.4^{\circ}$ & $69.15^{\circ}$ \\
\hline $4.99 \mu \mathrm{m}$ & $5.07 \mu \mathrm{m}$ & $5.29 \mu \mathrm{m}$ & $5.62 \mu \mathrm{m}$ & $6.24 \mu \mathrm{m}$ & $6.89 \mu \mathrm{m}$ & $3.88 \mu \mathrm{m}$ \\
\hline $222.1^{\circ}$ & $229.5^{\circ}$ & $251.5^{\circ}$ & $287.9^{\circ}$ & $338.2^{\circ}$ & $41.46^{\circ}$ & $116.9^{\circ}$ \\
\hline $5.51 \mu \mathrm{m}$ & $5.56 \mu \mathrm{m}$ & $5.74 \mu \mathrm{m}$ & $6.24 \mu \mathrm{m}$ & $6.89 \mu \mathrm{m}$ & $3.50 \mu \mathrm{m}$ & $4.46 \mu \mathrm{m}$ \\
\hline $287.9^{\circ}$ & $295.2^{\circ}$ & $316.8^{\circ}$ & $352.4^{\circ}$ & $41.46^{\circ}$ & $103.4^{\circ}$ & $177.4^{\circ}$ \\
\hline $6.24 \mu \mathrm{m}$ & $6.39 \mu \mathrm{m}$ & $6.81 \mu \mathrm{m}$ & $6.89 \mu \mathrm{m}$ & $3.50 \mu \mathrm{m}$ & $4.30 \mu \mathrm{m}$ & $5.07 \mu \mathrm{m}$ \\
\hline $6.472^{\circ}$ & $13.51^{\circ}$ & $34.49^{\circ}$ & $69.15^{\circ}$ & $116.9^{\circ}$ & $177.4^{\circ}$ & $249.7^{\circ}$ \\
\hline $2.78 \mu \mathrm{m}$ & $3.01 \mu \mathrm{m}$ & $3.40 \mu \mathrm{m}$ & $3.88 \mu \mathrm{m}$ & $4.46 \mu \mathrm{m}$ & $5.07 \mu \mathrm{m}$ & $5.72 \mu \mathrm{m}$ \\
\hline
\end{tabular}




\section{Reflectarray and Transmitarray Using the Same Structure}

The chess board unit cells arrangement is used for reflectarray and transmitarray mode of operation in the same time using two DC-voltage biasing. In the chess board structure, the graphene sheet behaves as conductor and dielectric successively by rearranging the applied biased DC-voltages between the different pieces of the graphene sheet $\left(\mu_{c}=0\right.$ or $\mu_{c}=1$ ). The 3D power pattern of the reflectarray and transmitarray in the same structure is shown in Figure 11(a). Power pattern of the reflectarray and transmitarray in the same structure is shown in Figure 11(b). The array introduces two maximum beams at $\theta=20^{\circ}$ (transmitarray mode) and at $\theta=160^{\circ}$ (reflectarray mode). The maximum gain for the transmitting beam is $18.5 \mathrm{~dB}$ and for reflecting beam is $19 \mathrm{~dB}$. The HPBW is $8^{\circ}$ for transmitarray and reflectarray, respectively. Figure 12 shows another example for reflectarray and transmitarray in the same structure, but at different angles $\theta=30^{\circ}$ (transmitarray mode) and $\theta=-150^{\circ}$ (reflectarray mode). Maximum gain at $\theta=30^{\circ}$ is $16.5 \mathrm{~dB}$ and at $\theta=-150^{\circ}$ is $14.5 \mathrm{~dB}$. Transmitarray and reflectarray HPBW are $6.6^{\circ}$ and $9^{\circ}$, respectively.

\section{Conclusion}

The design of $13 \times 13$ unit cell elements transmitarray/reflectarray from perforated dielectric sheet with inserted graphene sheet is proposed for bi-function antenna in $\mathrm{THz}$ communication band. The proposed structure is used to reflect or transmit the incident plane wave from the feeder using a single DC bias. The graphene sheet is considered as a conductor with $\mu_{\mathrm{c}}=1$, while in the second case, the graphene sheet is considered as a dielectric with $\mu_{c}=0$, by altering the DC applied voltage. The reflectarray/transmitarray introduces maximum gain of 24.4

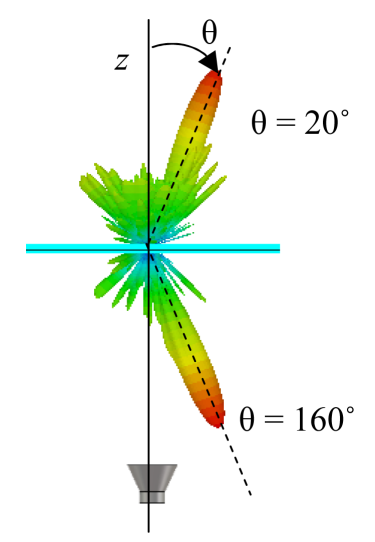

(a)

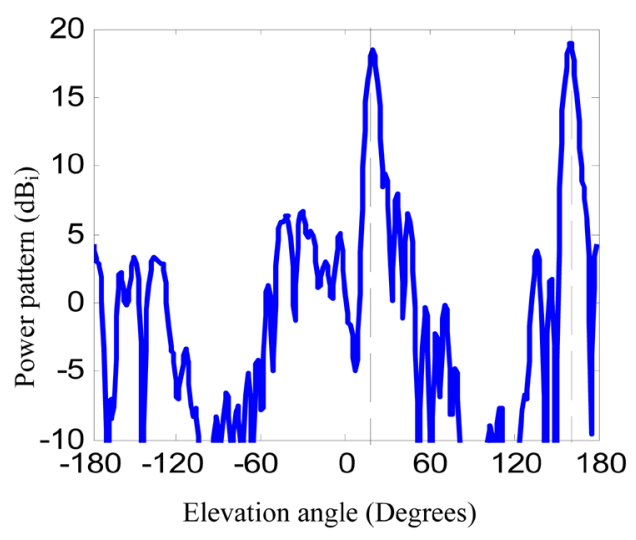

(b)

Figure 11. (a) The 3D power pattern of the reflectarray and transmitarray in the same structure, (b) power pattern of the reflectarray and transmitarray in the same structure.

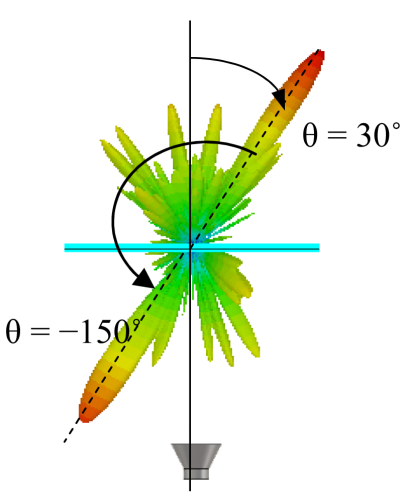

(a)

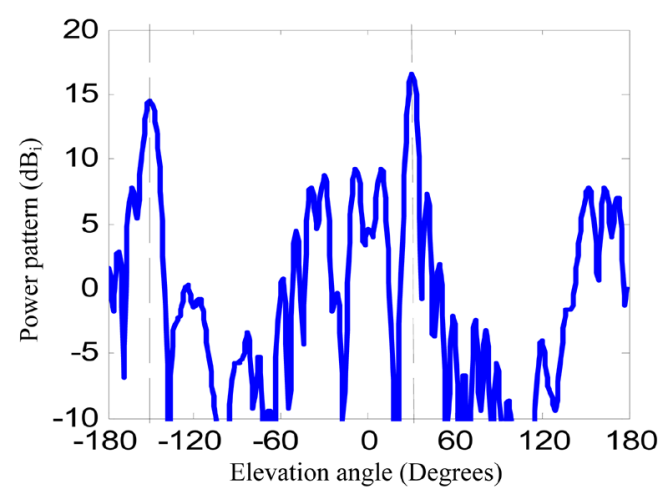

(b)

Figure 12. (a) The 3D power pattern of the reflectarray and transmitarray in the same structure, (b) power pattern of the reflectarray and transmitarray in the same structure. 
$\mathrm{dB} / 22 \mathrm{~dB}$ with the side lobe level of $-16.5 \mathrm{~dB} /-12 \mathrm{~dB}$ in the E-plane and $-19.5 \mathrm{~dB} /-15 \mathrm{~dB}$ in the H-plane. The 1-dB gain bandwidth is $1.07 \mathrm{THz} / 1 \mathrm{THz}$ with maximum gain occurs at $6 \mathrm{THz}$. Dual-beam reflectarray/transmitarray antenna is designed by rearranging the unit-cell elements in the array successively. The dual beam transmitarray introduces gain for $\zeta=0^{\circ}$ is $19.9 \mathrm{~dB}$ and for $\zeta=-20^{\circ}$ is $17.7 \mathrm{~dB}$. The chess board unit-cell element arrangement is used to construct reflectarray and transmitarray operation in the same time using a single structure. The array introduces two maximum beams at $\theta=20^{\circ}$ (transmitarray mode) and at $\theta=160^{\circ}$ (reflectarray mode). The maximum gain for the transmitting beam is $18.5 \mathrm{~dB}$ and for reflecting beam is $19 \mathrm{~dB}$. The HPBW is $8^{\circ}$ for transmitarray and reflectarray respectively. The same structure, but at different angles $\theta=30^{\circ}$ (transmitarray mode) and $\theta=-150^{\circ}$ (reflectarray mode). Maximum gain at $\theta=30^{\circ}$ is $16.5 \mathrm{~dB}$ and at $\theta=-150^{\circ}$ is 14.5 $\mathrm{dB}$. Transmitarray and reflectarray HPBW are $6.6^{\circ}$ and $9^{\circ}$, respectively. As proven in this paper, the calculation method can be successfully used for reflectarray and transmitarray in the same structure and in the same time. The tunability of grapheme conductivity introduces the bi-function characteristics of a single array structure in the THz band. The design depends on changing the graphene DC biasing voltage to transform the transmitting antenna to reflecting antenna. The compact structure of the antenna array saves the cost and the allocation area for the terahertz communication applications.

\section{References}

[1] Choi, W. and Lee, J. (2012) Graphene: Synthesis and Applications. CRC Press, Taylor \& Francis Group, Boca Raton.

[2] Yurduseven, O. (2011) Compact Parabolic Reflector Antenna Design with Cosecant-Squared Radiation Pattern. Microwaves, Radar and Remote Sensing Symposium, 25-27 August 2011, Kiev, 382-385.

[3] Rebeiz, G.M., Koh, K.J., Tiku, Y., Kang, D., Kim, C.Y., Atesal, Y., Cetinoneri, B., Kim, S.Y. and Shin, D. (2010) Highly Dense Microwave and Millimeter Wave Phased Array T/R Modules and Butler Matrices Using CMOS and SiGe RFICs. IEEE International Symposium on, Phased Array Systems and Technology (ARRAY), Boston, October 2010, 245-249.

[4] Ruphuy, M., Ren, Z. and Ramahi, O.M. (2014) Flat Far Field Lenses and Reflectors. Progress in Electromagnetics Research M, (PIER M), 34, 163-170.

[5] Huang, J. and Encinar, J.A. (2008) Reflectarray Antennas. IEEE Press, John Wiley and Sons, Hoboken.

[6] Al-Nuaimi, M.K. and Hong, W. (2014) Discrete Dielectric Reflectarray and Lens for E-Band with Different Feed. IEEE Antennas and Wireless Propagation Letters, 13, 947-950. http://dx.doi.org/10.1109/LAWP.2014.2313569

[7] Zainud-Deen, S.H., Gaber, S.M., Malhat, H.A. and Awadalla, K.H. (2013) Perforated Transmitaray-Enhanced Circularly Polarized Antenna for High-Gain Multi-Beam Radiation. 2013 International Symposium on Antennas and Propagation (ISAP 2013), Nanjing, October 2013, 484-487.

[8] Zainud-Deen, S.H., El-Shalaby, N., Gaber, S. M., Malhat, H.A. and Awadalla, K.H. (2012) Reflectarrays Mounted on or Embedded in Cylindrical or Spherical Surfaces. 2012 Middle East Conference on Antennas and Propagation (MECAP 2012), Cairo, 29-31 December 2012, 1-6.

[9] Dussopt, L., Kaouach, H., Lanteri, J. and Sauleau, R. (2011) Circularly-Polarized Discrete Lens Antennas in 60-GHz Band. Radio Engineering, 20, 733-738.

[10] Gaber, S.M. (2013) Analysis and Design of Reflectarrays/Transmitarrays Antennas. Ph.D Thesis, Faculty of Electronic Engineering, Menoufiya University, Menouf.

[11] Lau, J.Y. and Hum, S.V. (2012) A Wideband Reconfigurable Transmitarray Element. IEEE Transactions on Antennas and Propagation, 60, 1303-1311. http://dx.doi.org/10.1109/TAP.2011.2180475

[12] Lau, J.Y. and Hum, S.V. (2012) Reconfigurable Transmitarray Design Approaches for Beamforming Applications. IEEE Transactions on Antennas and Propagation, 60, 5679-5689. http://dx.doi.org/10.1109/TAP.2012.2213054

[13] Eridl, E., Topalli, K., Zorlu, O., Toral, T., Yildirim, E., Kulah, H. and Civi, O.A. (2013) A Reconfigurable Microfluidic Transmitarray Unit Cell. 7th European Conference on Antennas and Propagat (EUCAP), Gothenburg, 8-12 April 2013, 2957-2960.

[14] Abdelrahman, A.H., Nayeri, P., Elsherbeni, A.Z. and Yang, F. (2014) Analysis and Design of Wideband Transmitarray Antennas with Different Unit-Cell Phase Ranges. IEEE Antennas and Propagation Society International Symposium (APSURSI), Memphis, 6-11 July 2014, 1266-1267. http://dx.doi.org/10.1109/aps.2014.6904960

[15] Zainud-Deen, S.H., Hassen, W.M., Malhat, H.A. and Awadalla, K.H. (2015) Radiation Characteristics Enhancement of Dielectric Resonator Antenna Using Solid/Discrete Dielectric Lens. Advanced Electromagnetics, 4.

[16] Fujita, S. and Suzuki, A. (2013) Electrical Conduction in Graphene and Nanotubes. Wiley-VCH Verlag GmbH \& Co. KGaA, Weinheim. http://dx.doi.org/10.1002/9783527676668 
[17] Zhang, X.-L., Zhao, X., Liu, Z.-B., Liu, Y.-S., Chen, Y.-S. and Tian, J.-G. (2009) Enhanced Nonlinear Optical Properties of Graphene-Oligothiophene Hybrid Material. Optics Express, 17, 23959-23964. http://dx.doi.org/10.1364/OE.17.023959

[18] Bao, W. (2012) Electrical and Mechanical Properties of Graphene. PhD Thesis, University of California Riverside, Riverside.

[19] Grigorenko, A.N., Polini, M. and Novoselov, K.S. (2012) Graphene Plasmonics. Nature Photonics, 6, 749-758. http://dx.doi.org/10.1038/nphoton.2012.262

[20] Ren, X., Sha, W.E.I. and Choy, W.C.H. (2013) Tuning Optical Responses of Metallic Dipole Nanoantenna Using Grapheme. Optical Express, 21, 31824-31829. http://dx.doi.org/10.1364/OE.21.031824

[21] Lovat, G. (2012) Equivalent Circuit for Electromagnetic Interaction and Transmission through Graphene Sheets. IEEE Transactions on Electromagnetic Compatibility, 54, 101-109. http://dx.doi.org/10.1109/TEMC.2011.2169072

[22] Carrasco, E., Tamagnone, M. and Perruisseau-Carrier, J. (2012) Tunable Graphene Reflective Cells for THz Reflectarrays and Generalized Law of Reflection. Applied Physics Letters, 102, Article ID: 104103.

[23] Malhat, H.A., Zainud-Deen, S.H. and Gaber, S.M. (2014) Graphene Based Transmitarray for Terahertz Applications. Progress in Electromagnetics Research M, 36, 185-191. http://dx.doi.org/10.2528/PIERM14050705

[24] Malhat, H.A., Badawy, M.M., Zainud-Deen, S.H. and Awadalla, K.H. (2015) Plasma Reflectarray/Transmitarray Antennas Using a Single Structure. Plasmonics, 10, 1479-1487. http://dx.doi.org/10.1007/s11468-015-9956-8

[25] Carrasco, E., Tamagnone, M., Mosig, J.R., Low, T. and Perruisseau-Carrier, J. (2015) Gate-Controlled Mid-Infrared Light Bending with Aperiodic Graphene Nanoribbons Array. Nanotechnology, 26, Article ID: 134002. http://dx.doi.org/10.1088/0957-4484/26/13/134002

[26] Kong, X.-T., Khan, A.A., Kidambi, P.R., et al. (2015) Graphene-Based Ultrathin Flat Lenses. ACS Photonics, 2, 200207. http://dx.doi.org/10.1021/ph500197i

[27] User’s Manual of CST Microwave Studio 2012.

[28] Rouhi, N., Capdevila, S., Jain, D., et al. (2012) Terahertz Graphene Optics. Nano Research, 5, 667-678. http://dx.doi.org/10.1007/s12274-012-0251-0

[29] Hanson, G.W. (2008) Dyadic Green's Functions for an Anisotropic, Non-Local Model of Biased Grapheme. IEEE Transactions on Antennas and Propagation, 56, 747-757. http://dx.doi.org/10.1109/TAP.2008.917005 